\title{
Evaluation of prescription pattern and efficacy of anti-diabetic drugs in Coimbatore, India
}

\author{
*Nagarajaperumal Govindasamy ${ }^{1,2}$ and Mohan Sellappan² \\ ${ }^{1}$ Faculty of Pharmacy, Shri Jagdishprasad Jhabarmal Tibrewala University, Jhunjhunu-333001, Rajasthan, India \\ ${ }^{2}$ Department of Pharmacology, Karpagam College of Pharmacy, Coimbatore-641032, Tamil Nadu, India
}

\begin{abstract}
In this present study, 1500 Diabetes Mellitus (DM) patients were included from Coimbatore zone, Tamil Nadu, India. The blood glucose levels were monitored to correlate the glycemic control with the antidiabetic drug treatment. This study addressed many variabilities in such treatments including the prescribing pattern of various novel entities along with existing drugs for glycemic control, diabetic vascular complexities on Coimbatore zone, lack of relevant scientific data, occurrences of prescription errors, less awareness of the DM patients, the insufficient number of local hospitals and high cost of the medicine. Data analysis was carried out by segregating the DM patients under study according to their blood glucose level. Results demonstrated that brand names of antidiabetic drugs were taken more frequently by outpatients when contrasted with inpatients. Also, the number of drugs prescribed under generic names were significantly less than prescribe brand names. Prescribed formulations results indicated that tablets were preferred over other formulations. Frequently prescribed twenty-one brands and their combination results demonstrated the popularity of the insulin human Mixtard ${ }^{\circledR}$ injection 30-40 IU. Moreover, frequently prescribed 21 branded drugs' cost were analyzed. It can be concluded from the current work that appropriate steps should be taken to raise awareness of the DM patients in Coimbatore zone so that they can follow the specialists' instruction for better hyperglycemia control. Finally, it can be suggested that the Tamil Nadu Government should put more effort on improving health care support in Coimbatore zone.
\end{abstract}

Key Words: Diabetes Mellitus, Glucometer, Glycemic Control, Generic Names, Anti Diabetic Drugs, Insulin and Hyperglycemia.

\section{INTRODUCTION}

DM is constant metabolic dearth illness, standout amongst most pervasive sicknesses in the world. Report of International Diabetes Federation indicated 7.6\% (40.9 Millions) affected worldwide especially in our assumption to rise the prevalence $8.6 \%$ (60.9 Millions) at year of 2025 (Srinivasan, et al., 2017). In our assumption $50 \%$ of Indian hospitals not follow the guidelines due to nonpharmacological treatment does not prompt commendable for glycemic control, patients ought to get Oral Hypoglycemic Agents (OHAs), insulin and both (Seema and Cornwall, 2014). The past study indicated India, three pharmacologic classes of accessible formulations in the National List of Essential Medicines such as biguanide (Metformin), sulfonylureas (Glibenclamide and Gliclazide) and insulin derivatives were prescribed drug cost more (48.2\%) (Agarwal et al., 2014). Based on the above reasons interested to analyze the current scenario of prescription pattern and efficacy of antidiabetic drugs on Coimbatore.

\section{MATERIALS AND METHODS}

\section{Study design}

A few writing overview based to choose Cohort study (Hiroyuki et al., 2010) was utilized to appraise the different parameters of DM patients on different zone of Coimbatore and which incorporates south east west and north zones which includes inpatients and outpatients.

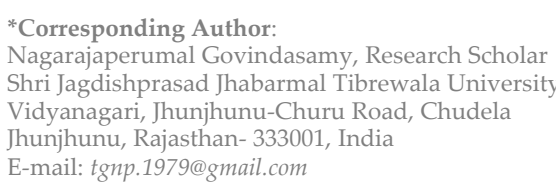

\section{Sample size}

Chosen associate study based to1500 DM patients (Mandavi et al., 2012; Govan et al., 2012) were gathered from Karpagam Medical College-Hospital and different multispecialty hospitals.

\section{Study Criteria}

Inclusion (Dobesh, 2006; Derosa, 2008)

1. Patients above 18 years and under 60 years old.

2. Patients with DM with other co-morbidities.

3. Collected data from inside the hospital which includes inpatients and outpatients.

4. Patients able to read and write

5. Patients regularly consuming diabetic medication.

6. End of the days tallied DM Patients.

Exclusion (Alvarez et al., 2008)

1. Patients aged below 18 years or over 60 years.

2. Patients without doctor authorization, attenders and spectators permitted inside branch of diabetology.

3. Bogus information of other classification wellbeing sciences people groups given data were not gathered.

4. Patients, who were in obviousness to be dismisses in our study.

Based on the above criteria to direct patients advising in drug information center.

\section{Observed parameters}

As per the guidelines instructions (Coilin and Dejan, 2005; Phil Edwards, 2010) observing some parameters such as glucose level of the patients, (Andreas, et al., 2014), rate of inpatients and outpatients (Chen et al., 2012), analysis of prescription (Which includes monotherapy and polytherapy) (David, et al., 2009) Adverse Drug Reaction Monitoring (Dabhade et al., 2013) and its Cost wise comparison (Adrian et al.,2010). 


\section{RESULTS AND DISCUSSION}

\section{Clinical condition}

The Table 1 and Figure 1, have been indicated deliberate glucose levels help to separate the DM Patients. The DM patients' glucose level alterations were indicated that the increased Glucose levels such as slightly increased glucose level with DM $(19.1 \pm 0.0)$, DM Type-I $(74.5 \pm 2.74)$ DM Type-II $(173.5 \pm 6.85)$ when compared to normal healthy volunteer $(125.7 \pm 2.73)$.

\section{Prescription pattern analysis for inpatients and out patients} The aggregate number of medicines took care of 1500 patients, which incorporates inpatients and outpatients comes about demonstrated (Table 2 and Figure 3) that the out patients were more taken care of (1078 Numbers and $71.9 \%$ ) when contrasted with inpatients (422 Numbers and $28.1 \%)$. The aftereffect of inpatients showed that the type- I DM solutions (228 Numbers and $15.2 \%$ ) were progressively when thought about type II DM remedies (788 Numbers and $52.5 \%)$ furthermore out patients of type II DM medicine (788 Numbers and $52.5 \%$ ) were more contrasted with type- I DM remedies (290 Numbers and 19.4\%).

\section{Analysis of prescriptions}

The results (Table 3 and Figure 4) of drugs prescribed under generic names (1405 Numbers $32.1 \%$ ) were less drugs when compared to prescribe brand names (2839 Numbers and $65 \%$ ) for DM associated diseases. The prescription containing different brands of anti-diabetic drugs results indicated that the drugs prescribed under brand names 127 Numbers and $2.6 \%$ ) when compared to prescribed brand names (2839 Numbers and 65\%) for DM associated diseases. The single drugs are prescribed under the guidelines (768 Numbers and $17.5 \%$ ) were comparatively increased to prescribe combinations under the guidelines (668 Numbers and 15.3). The guidelines based prescribed drugs and authenticated prescriptions reports indicated that the based on the guidelines to prescribed drugs (4265 Numbers and 97.6\%) and prescriptions (1388 Numbers and $92.5 \%$ ) were more when compared to randomly prescribed drugs (106 Numbers and $2.4 \%$ ) and prescriptions (112 Numbers and 7.5\%).

\section{Mono therapy of prescriptions}

The recommended drugs example of mono treatment comes about showed (Table 4 and Figure 6) that the aggregate quantities of single medications endorsed in the 345 medicines and Type-I DM endorsed tranquilizes in the solutions were more numbers and rate (184 Numbers and $53.3 \%$ ) when contrasted with Type-II and Severe Diabetes Mellitus. The extreme state of DM to recommend tranquilizes in the solutions were more (107 numbers and 31\%) when contrasted and Type-II DM remedies (54 numbers and $15.7 \%)$.

\section{Analysis different formulations}

In our study different formulations prescribed (Table 5 and Figure 7-8) by the doctors, which expressed that the totally 4371 numbers of formulations were used for the treatment of DM and its associated diseases in Coimbatore zone which includes tablets, capsules, injections, ointments, syrups, creams, jelly, aersol and suppositories. The results of prescribed formulations tablets were present in the more numbers in the prescriptions when compared to capsules (967 Numbers and 22.1\%), injections (512 Numbers and $11.7 \%$ ), ointments (15 Numbers and $0.3 \%$ ), syrups (64 Numbers and $1.5 \%)$, creams (13 Numbers and $0.3 \%)$, jelly (18 Numbers and $0.4 \%$ ), aersol (5 Numbers and $0.1 \%$ ) and suppositories (8 Numbers and $0.2 \%$ ).
Analysis of different branded drugs

The FDA approved drugs were prescribed (Table 6 and Figure 9) (2839 Numbers and 65\%) when compared with total number of drugs (4371 Numbers) and also FDA un approved drugs were very less to prescribed (22 Numbers and $0.5 \%$ ) and (22 Numbers and $1.5 \%$ ) when compared to total number of drugs (4371 Numbers) and FDA approved drugs and (Numbers and 7.5\%). Twenty-two brands were frequently prescribed drugs in the prescriptions which indicated that the 2819 Numbers and $34.6 \%$ and 2819 Numbers and $99.3 \%$ were not frequently prescribed brands when compared to total number of drugs (4371 Numbers) and FDA approved drugs (23 Numbers and $0.5 \%)$ and (23 Numbers and $1.5 \%$ ).

\section{Analysis of frequently prescribed brands}

The frequently prescribed twenty-one brands to the DM Patients results expressed that (Table 7 and Figure 11-12) the insulin human Mixtard injection 30-40 IU injection were prescribed (Numbers 142 and 17.1\%) more for Type-I DM patients when compared to each other brands. The Glycomet (Metformin, $500 \mathrm{mg}$ ) brand of drugs prescribed more (135 Numbers $16.1 \%$ ) for Type-II DM when compared to other brands except insulin human Mixtard injection 30-40 IU injection were prescribed (Numbers 142 and 17.1\%). The Gemer (Glimipride 2mg/Metformin 500mg) brand of drugs prescribed more (113 Numbers $13.5 \%$ ) for Type-II DM patients when compaered to other brands not included insulin human Mixtard injection 30-40 IU injection were prescribed (Numbers 142 and 17.1\%) and Glycomet (Metformin,500mg) (135 Numbers 16.1\%). The reports of Diapride (Glimipride 2mg) (109 Numbers 13\%) brand of drugs prescribed for Type-II DM patients when compared to K-glim (Glimipride1mg/ Metformin 500mg) (32 Numbers $3.9 \%$ ), Janumet (Metformin 50mg and Sitagliptin1000mg) (31 Numbers 3.8\%), Istamet (Metformin50mg and Sitagliptin 1000mg) (31 Numbers 3.8\%), Glvus Met (Metformin 50mg and Vitagliptin 1000mg) (21 Numbers 2.5\%), Glimy -M(Glimipride 2mg/ Metformin 500mg) (20 Numbers 2.4\%), Gluconorm (Glimipride 2mg / Metformin 500mg), (22 Numbers 2.6\%), Ppg (Voglibose $0.3 \mathrm{mg}$ ) (24 Numbers 2.9\%), Diamicron XR (Gliclazide 60mg) (15 Numbers 1.8\%), Tenglyn (Teneligliptin $20 \mathrm{mg}$ ) (14 Numbers $1.7 \%$ ), Trejenta (Linagliptin $5 \mathrm{mg}$ ) (15 Numbers $1.8 \%$ ), Glimy (Glimipride1mg / Metformin 500mg) (135 Numbers $16.1 \%$ ), Glimisave - M (Glimipride 1mg / Metformin 500mg) (21 Numbers 2.5\%), Glizid (Gliclazide 40mg) (10 Numbers 1.2\%), K-Gem (Gliclazide $80 \mathrm{mg} /$ Metformin 50mg) (13 Numbers 1.6\%) and Blisto (Glimipride 4mgv/ Metformin 1000mg) (135 Numbers 16.1\%) brands but except insulin human Mixtard injection 30-40 IU injection were prescribed (Numbers 142 and 17.1\%) and Glycomet (Metformin,500mg) (135 Numbers 16.1\%).

\section{Analysis of cost wise comparison}

The cost wise analysis of frequently prescribed twenty-one branded drugs (Table 8 and Figure 12) total cost Rs. 29882.55/.. The human Mixtard insulin 30-40 IU has been prescribed for the treatment of Type-II DM Patients more cost Rs. 22436.00/- for 142 drugs when compared to each other brands of drugs. The Glimy-M single tablet is RS. 53, our finding collected prescriptions 20 Numbers, which total cost Rs.1060/- but when compared to single tablet more economic when compared to each other drugs except human Mixtard insulin 30-40 IU. Same combinations but cost 

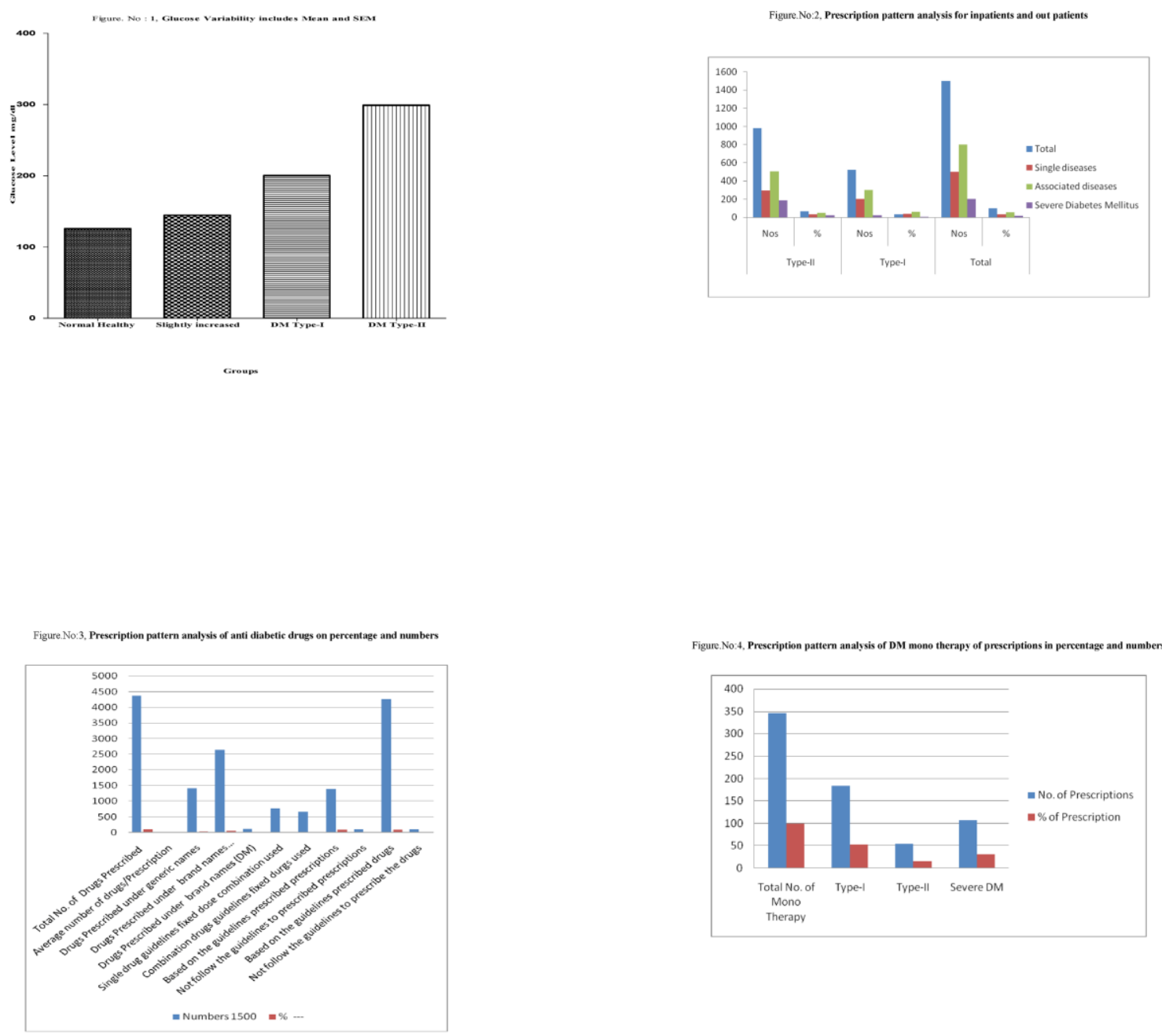

Figure No.5, Number of Formulations Prescribed
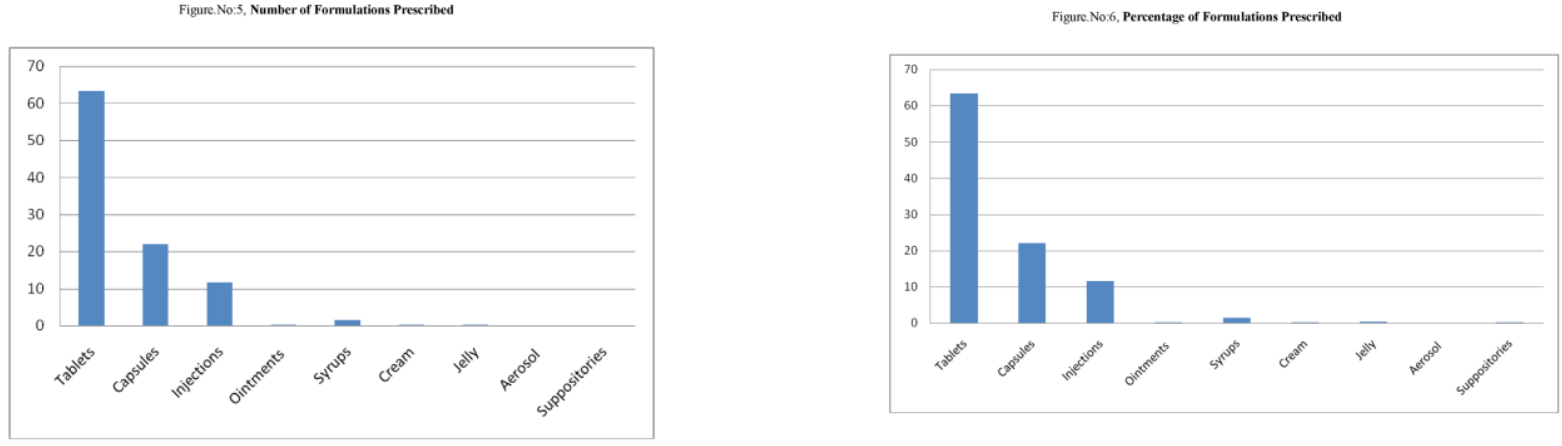

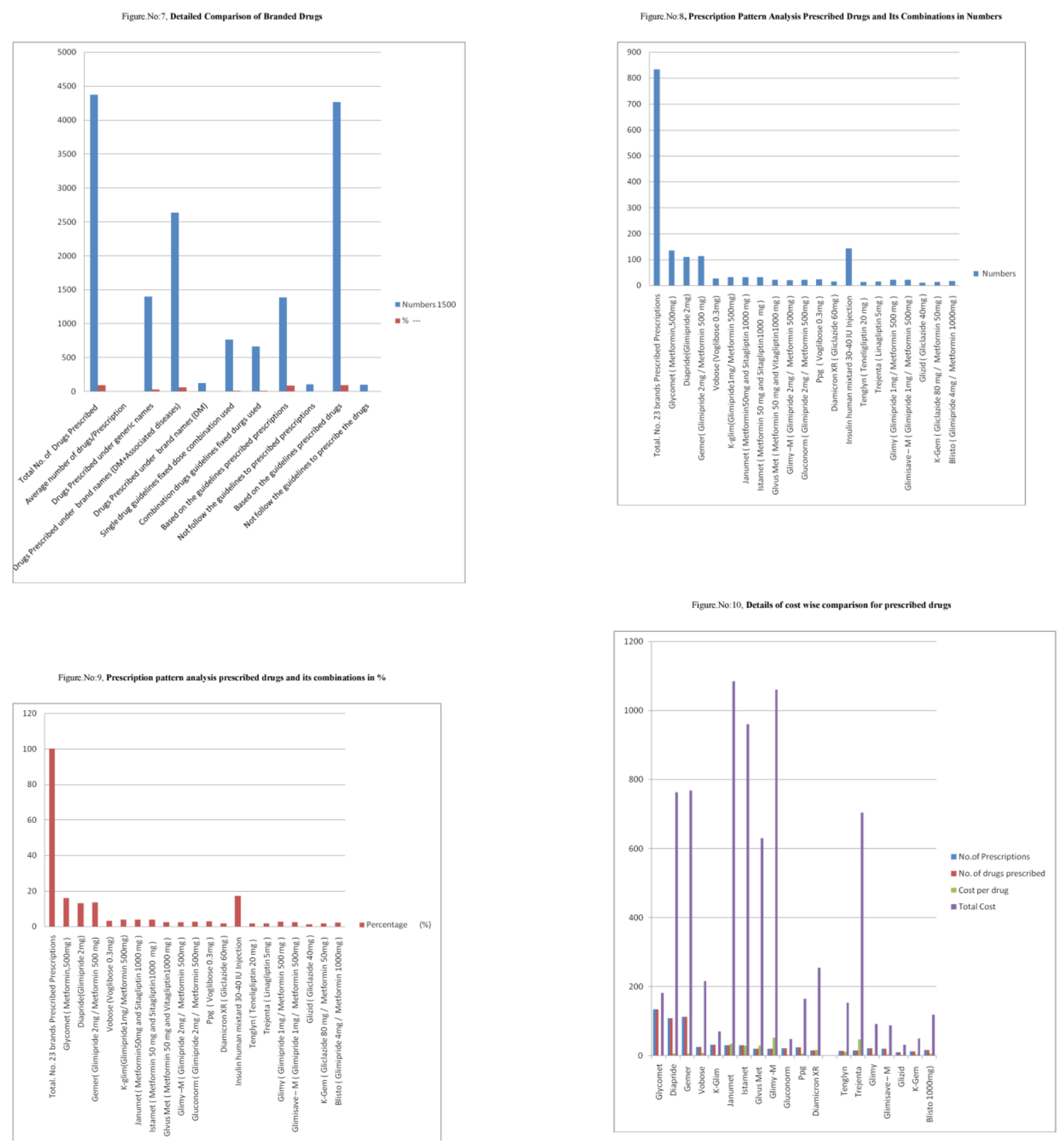
Table 1: Clinical Condition of the DM patients.

\begin{tabular}{clc}
\hline $\begin{array}{c}\text { S. } \\
\text { No }\end{array}$ & \multicolumn{1}{c}{ Disease } & $\begin{array}{c}\text { Glucose level } \\
(\mathbf{m g} / \mathbf{d L})\end{array}$ \\
\hline 1 & Normal Healthy Volunteers & $125.7 \pm 2.73$ \\
2 & Slightly increased Glucose level with DM & $144.6 \pm 2.73$ \\
3 & DM Type-I & $200.2 \pm 5.47^{* * *}$ \\
4 & DM Type-II & $299 \pm 9.58^{* * *}$ \\
\hline Above glucose level were expressed $(\mathrm{N}=30)$ Mean \pm SEM and indication \\
$(\mathrm{P}<0.05)^{*},(\mathrm{P}<0.001)^{* *}$ and $(\mathrm{P}<0.0001)^{* * *}$
\end{tabular}

Table 3: Analysis of Prescriptions.

\begin{tabular}{|c|c|c|c|}
\hline $\begin{array}{l}\text { S. } \\
\text { No }\end{array}$ & Particulars & No. & $\%$ \\
\hline 1 & Total No. of Prescription & 1500 & - \\
\hline 2 & Total No. of Drugs Prescribed & 4371 & 100 \\
\hline 3 & Average number of drugs/Prescription & 2.9 & - \\
\hline 4 & Drugs Prescribed under generic names & 1405 & 32.1 \\
\hline 5 & Drugs Prescribed under brand names (DM & & \\
\hline & +Associated diseases) & 2638 & 65 \\
\hline 6 & Drugs Prescribed under brand names(DM) & 127 & 2.9 \\
\hline & $\begin{array}{l}\text { Single drug guidelines fixed dose combina- } \\
\text { tion used }\end{array}$ & 768 & 17.5 \\
\hline 8 & $\begin{array}{l}\text { Combination drugs guidelines fixed drugs } \\
\text { used }\end{array}$ & 668 & 15.3 \\
\hline & $\begin{array}{l}\text { Based on the guidelines prescribed prescrip- } \\
\text { tions }\end{array}$ & 1388 & 92.5 \\
\hline 10 & $\begin{array}{l}\text { Not follow the guidelines to prescribed pre- } \\
\text { scriptions }\end{array}$ & 112 & 7.5 \\
\hline 11 & Based on the guidelines prescribed drugs & 4265 & 97.6 \\
\hline 12 & $\begin{array}{l}\text { Not follow the guidelines to prescribe the } \\
\text { drugs }\end{array}$ & 106 & 2.4 \\
\hline
\end{tabular}

Table 5: Analysis different formulations by the help of collected prescriptions.

\begin{tabular}{clcc}
\hline $\begin{array}{c}\text { S. } \\
\text { No }\end{array}$ & Formulations & $\begin{array}{c}\text { No. of } \\
\text { formulations }\end{array}$ & $\begin{array}{c}\text { \% of } \\
\text { formulations }\end{array}$ \\
\hline 1 & Tablets & 2769 & 63.4 \\
2 & Capsules & 967 & 22.1 \\
3 & Injections & 512 & 11.7 \\
4 & Ointments & 15 & 0.3 \\
5 & Syrups & 64 & 1.5 \\
6 & Cream & 13 & 0.3 \\
7 & Jelly & 18 & 0.4 \\
8 & Aerosol & 5 & 0.1 \\
9 & Suppositories & 8 & 0.2 \\
\hline \multicolumn{4}{c}{ Total No. of prescribed } \\
& drugs & \multicolumn{2}{|}{} \\
\hline
\end{tabular}

Table 2: Prescription pattern analysis for in-patients and outpatients.

\begin{tabular}{cccccccc}
\hline S. & Different types & \multicolumn{2}{c}{ Type-II } & \multicolumn{2}{c}{ Type-I } & \multicolumn{2}{c}{ Total } \\
\cline { 3 - 8 } No & of Prescription & No & $\%$ & No & $\%$ & No & $\%$ \\
\hline 1 & Total & 982 & 65.5 & 518 & 34.5 & 1500 & 100 \\
2 & In Patients & 194 & 12.9 & 228 & 15.2 & 422 & 28.1 \\
3 & Out Patients & 788 & 52.5 & 290 & 19.4 & 1078 & 71.9 \\
\hline
\end{tabular}

Table 4: Analysis Mono Therapy of Prescribed medication for DM.

\begin{tabular}{clcc}
\hline $\begin{array}{c}\text { S. } \\
\text { No }\end{array}$ & Clinical condition & $\begin{array}{c}\text { No. of } \\
\text { prescriptions }\end{array}$ & $\begin{array}{c}\text { \% of } \\
\text { prescriptions }\end{array}$ \\
\hline 1 & Total No. of Mono Therapy & 345 & 100 \\
2 & Type-I & 184 & 53.3 \\
3 & Type-II & 54 & 15.7 \\
4 & Severe DM & 107 & 31.0 \\
\hline
\end{tabular}


Table 6: Analysis of different branded drugs.

\begin{tabular}{cllr}
\hline $\begin{array}{c}\text { S. } \\
\text { No }\end{array}$ & Particulars & Numbers & $\%$ \\
\hline 1 & Total No. of Prescription & 1500 & - \\
2 & Total No. of Drugs Prescribed & 4371 & 100 \\
3 & Prescribed branded drugs (FDA Approved) & 2839 & 65.0 \\
4 & Prescribed branded drugs (Not FDA Approved) & 1532 & 100 \\
5 & Frequently prescribed brands & 22 brands for anti-diabetic drugs / 833 times for repeatedly & 0.5 \\
& & prescribed in the prescriptions / Out of 1500 prescription & 54 \\
6 & Not frequently prescribed brands & 2819 & $34.5 \quad 99.3$ \\
\hline
\end{tabular}

Table 7: Analysis of frequently prescribed brands.

\begin{tabular}{lccc}
\hline Frequently Prescribed Brands in prescription & No. & \% \\
\hline Total 21 brands Prescribed Prescriptions & 833 & 100 \\
Glycomet (Metformin, 500mg) & 135 & 16.1 \\
Diapride(Glimipride 2mg) & 109 & 13.0 \\
Gemer(Glimipride 2mg / Metformin 500 mg) & 113 & 13.5 \\
Vobose (Voglibose 0.3mg) & 26 & 3.1 \\
K-glim(Glimipride1mg/ Metformin 500mg) & 32 & 3.9 \\
Janumet (Metformin50mg and Sitagliptin 1000 mg) & 31 & 3.8 \\
Istamet (Metformin 50 mg and Sitagliptin 1000 mg) & 31 & 3.8 \\
Glvus Met (Metformin 50 mg and Vitagliptin 1000 mg) & 21 & 2.5 \\
Glimy -M (Glimipride 2mg / Metformin 500mg) & 20 & 2.4 \\
Gluconorm (Glimipride 2mg / Metformin 500mg) & 22 & 2.6 \\
Ppg (Voglibose 0.3mg) & 24 & 2.9 \\
Diamicron XR (Gliclazide 60mg) & 15 & 1.8 \\
Insulin human mixtard 30-40 IU Injection & 142 & 17.1 \\
Tenglyn (Teneligliptin 20 mg) & 14 & 1.7 \\
Trejenta (Linagliptin 5mg) & 15 & 1.8 \\
Glimy (Glimipride 1mg / Metformin 500 mg) & 22 & 2.6 \\
Glimisave - M (Glimipride 1mg / Metformin 500mg) & 21 & 2.5 \\
Glizid (Gliclazide 40mg) & 10 & 1.2 \\
K-Gem (Gliclazide 80 mg / Metformin 50mg) & 13 & 1.6 \\
Blisto (Glimipride 4mg / Metformin 1000mg) & 17 & 2.1 \\
\hline
\end{tabular}

Table 8: Analysis of cost wise comparison.

\begin{tabular}{|c|c|c|c|c|c|}
\hline S. No & Frequently prescribed brands & $\begin{array}{c}\text { No. of } \\
\text { prescriptions }\end{array}$ & $\begin{array}{c}\text { No. of drugs } \\
\text { prescribed }\end{array}$ & Cost per drug & Total Cost \\
\hline 1 & Glycomet & 135 & 135 & 1.35 & 182.25 \\
\hline 2 & Diapride & 109 & 109 & 7 & 763.00 \\
\hline 3 & Gemer & 113 & 113 & 6.8 & 768.40 \\
\hline 4 & Vobose & 26 & 26 & 8.3 & 215.80 \\
\hline 5 & K-Glim & 32 & 32 & 2.2 & 70.40 \\
\hline 6 & Janumet & 31 & 31 & 35 & 1085.00 \\
\hline 7 & Istamet & 31 & 31 & 30 & 960.00 \\
\hline 8 & Glvus Met & 21 & 21 & 30 & 630.00 \\
\hline 9 & Glimy -M & 20 & 20 & 53 & 1060.00 \\
\hline 10 & Gluconorm & 22 & 22 & 2.2 & 48.40 \\
\hline 11 & Ppg & 24 & 24 & 6.9 & 165.60 \\
\hline 12 & Diamicron XR & 15 & 15 & 17 & 255.00 \\
\hline 13 & Insulin human mixtard 30-40 IU Injection & 142 & 142 & 158 & 22436.00 \\
\hline 14 & Tenglyn & 14 & 14 & 11 & 154.00 \\
\hline 15 & Trejenta & 15 & 15 & 47 & 705.00 \\
\hline 16 & Glimy & 22 & 22 & 4.2 & 92.40 \\
\hline 17 & Glimisave - M & 21 & 21 & 4.2 & 88.20 \\
\hline 18 & Glizid & 10 & 10 & 3.2 & 32.00 \\
\hline 19 & K-Gem & 13 & 13 & 3.8 & 49.40 \\
\hline 20 & Blisto (1000mg) & 17 & 17 & 7 & 119.00 \\
\hline \multicolumn{5}{|c|}{ Total } & 29882.55 \\
\hline
\end{tabular}


wise differ from brand to brand report indicated that the Glimy-M (Glimipride 2mg / Metformin 500mg) Rs. 1060.00/- for 20 tablets but single tablet Rs.53/- brand more expensive when compared to each other brands such as Gemer (Glimipride 2mg / Metformin 500mg) Rs.768.40/- for 113 tablets but single tablet Rs.6.8/- , Blisto (Glimipride 4mg / Metformin 1000mg), Rs.119 /- for 17 tablets but single tablet Rs.17/-, Glimy (Glimipride 1mg / Metformin 500 mg)) Rs.92.40/- for 22 tablets but single tablet Rs.4.2/- , Glimisave - M (Glimipride 1mg / Metformin 500mg) Rs.88.20/- for 21 tablets but single tablet Rs.4.2/-, , K-glim(Glimipride1mg / Metformin 500mg) Rs.70.40/- for 32 tablets but single tablet Rs.2.2/- and Gluconorm (Glimipride 2mg / Metformin 500mg) Rs.48.40 /- for 32 tablets but single tablet Rs.2.2/-. Single drug same moiety (working mechainism same) but differ the cost comparison statement indicated that the Diapride (Glimipride 2mg) Rs.763/- for 109 tablets but single tablet Rs.7/- have more economic when compared to Glizid (Gliclazide, 40mg) Rs.32/- for 10 tablets but single tablet Rs.3.2/-, Glycomet (Metformin, 500mg) Rs.182.25/- for 135 tablets but single tablet Rs.1.35/-and Diamicron XR (Gliclazide 60mg) Rs.255/- for 15 tablets but single tablet Rs.17/-. Single drug same dose different brands to change the cost Vobose (Voglibose 0.3mg) Rs.215.80/- for 26 tablets but single tablet Rs.8.3 /- were comparatively less expensive to Ppg (Voglibose 0.3mg) Rs.165.60/- for 24 tablets but single tablet Rs.6.9/- and also Glizid (Gliclazide 40mg) Rs.32/- for 10 tablets but single tablet Rs.3.2/- were moderately less luxurious to Diamicron XR (Gliclazide 60mg) Rs.255/- for 15 tablets but single tablet Rs.17/-. Single drug new moiety comparison report indicated that the Trejenta (Linagliptin 5mg), Rs.705 /- for 15 tablets but single tablet Rs.15/-, have more expensive when compared to Tenglyn (Teneligliptin $20 \mathrm{mg}$ ) Rs.154 /- for 14 tablets but single tablet Rs.11/- but above drugs working mechanism is same.

\section{CONCLUSION}

The recommending practices of our study signs were not tasteful, to be proposed by medications of poly pharmacy, over remedy of against diabetic medications and absence of awareness of essential medications list. The endeavor of the enrolled drug specialist has the capacity to be effective and understanding fulfillment can be accomplished just if the patient gets objective treatment for lessen pervasiveness of Diabetes Me and related maladies in Coimbatore zone. This study will be demonstrated input to the enlisted drug specialist for make readiness about sane utilization of against diabetic medications. The clinic models ought to be molded according to the nearby prerequisite, for the most part important hostile to diabetic medications were kept up recommended and put away by determined in standard rules. The enlisted drug specialist must be certain to endorse the counter diabetic medications by the assistance of standard rules. In view of the above articulation predetermined number of hostile to diabetic medications will be recommended by the enrolled drug specialist and specialists for decrease of unnecessary use on exorbitant medications. Specialists and drug specialist ought to recommend on account of social perspective, which will be valuable for country development and decrease of financial issues. To create the awareness to DM patients that the fixed goals are not suitable for all patients, particularly age group of DM patients will follow the pharmacist instruction to control the hyperglycemia and prevent vascular complications in type-II and I Diabetes Mellitus.

\section{ACKNOWLEDGEMENT}

We wish to express gratitude towards Shri Jagdishprasad Jhabarmal Tibrewala University and the Head, Department of Pharmacy, Rajasthan, Karpagam College of Pharmacy, Tamil Nadu, for expansion of heartfelt support for our research.

\section{REFERENCES}

Adrian, N.C. L., Terence, T., Henry. H., Kevin. T., and Catherine H.Y. Y. (2012) Initiating insulin in patients with type 2 diabetes. CMAJ, 184(7): 767-776. [DOI]

Agarwal, A.A., Jadhav P. R and Deshmukh Y. A. (2014). Prescribing pattern and efficacy of anti-diabetic drugs in maintaining optimal glycemic levels in diabetic patients. Journal of Basic and Clinical Pharmacy, 5(3):79-83. [DOI]

Alvarez, A. C., Russell N.M., Edwards, K.L., Shane Greene, L.M., Chastain Rick, A. W and Anthony J. B. (2008). Combination thiazolidinedione and fibrate effect on high-density lipoprotein cholesterol (HDL-C) concentration in a Veterans Affairs patient population. J Clini Lipidol, 4, (2): 447-452. [DOI]

Andreas F.H.P., Med and Harald H Klein med. (2014). The Treatment of Type 2 Diabetes. Dtsch Arztebl Int,111, (5): 69-82.

Chen, S A., Chao, T F., Chan, W. L., Chen, J. W., Huang, C. C., Leu, H. B and Lin, S. J. (2012). Thiazolidinediones can prevent new onset atrial fibrillation in patients with non-insulin dependent diabetes. Int J Cardiol,56,(2):199-202. [DOI]

Coilin, D.M and Dejan, L. (2005). Updated projections of global mortality and burden of disease, 2002-2030: data sources, methods and results. WHO, 1-100. [DOI]

Dabhade, S., Deepak, B.D and Atrekavita. (2013). Review on Pharmacovigilance study of Telmisartan in Hypertension Patients, Asian J Pharm Clin, 6,(3):17-20.

Danaei, G., Finucane, M. M., Lu, Y., Singh, G.M., Cowan M. J and Paciorek C. J. (2011). National, Regional and global trends in fasting plasma glucose and diabetes prevalence since 1980: systematic analysis of health examination surveys and epidemiological studies with 370 countryyears and 2.7 millionparticipants. Lancet, 48,(378): 31-40. [DOI]

David, M. N., John, B. B., Mayer B. D., Ele Ferrannini., Rury R. H, Robert Sherwin and Bernard Zinman., (2009). Medical Management of Hyperglycemia in Type 2 Diabetes: A Consensus Algorithm for the Initiation and Adjustment of Therapy. Diabetes Care,32(1): 193-203. [DOI]

Derosa, G., Angelo, A. D., Rangonesi, PD., Arrigo Francesco Giuseppe Cicero. (2008). Metabolic effects of pioglitazone and rosiglitazone in patients with diabetes and metabolic syndrome treated with metformin. Internal Medicine Journal 37(2):79-86. [DOI]

Dobesh, P.P. (2006). Stable angina: Current state of disease management. J Manag Crae Pharm,12,(8):4-9. [DOI]

Govan, L., Maietti, E., Torsney, B., Briggs, A and Colhoun, H.M. (2012) The Side effects of deprivation and $\mathrm{HbA} 1 \mathrm{c}$ on admission to hospital for diabetic ketoacidsis in type 1diabetes. Diabetol, 55,(9):2356-2360. [DOI]

Hiroyuki, S., Toshimi. S., Hiroyasu, I., Fujiko, I., Emiko. O. Kiyoji. T., Hitoshi. O and Takashi. M. (2010). Relationship Between Obesity and Incident Diabetes in Middle-Aged and Older Japanese Adults: The Ibaraki Prefectural Health Study. Myo Clinic Pro, 85(1): 36-40. [DOI]

Mandavi, S. D., Cruz., Atul Sachdev and Pramil Tiwari. (2012). Adverse drug Reactions \& their risk factors among Indian ambulatory elderly patients. Ind J Med Res,136,(4):404- 410. PMID: 23041733

Phil Edwards. (2010). Questionnaires in clinical trials: guidelines for optimal design and administration. 66,(8): 271-273. [DOI]

Seema, A. K and Jon Cornwall. (2014). The current state of diabetes mellitus in India. Australas Med J, 7(1): 45-48. PMID: 24567766

Srinivasan S, Swaminathan G, Kulothungan V, Ganesan S, Sharma T, Raman R (2017). Age-related macular degeneration in a South Indian population, with and without diabetes.Eye (Lond)..20, (25), 20-25 [DOI] 